Article

\title{
Iron-Based Electrocatalysts for Energy Conversion: Effect of Ball Milling on Oxygen Reduction Activity
}

\author{
Maida Aysla Costa de Oliveira ${ }^{\circledR}$, Pedro Pablo Machado Pico $₫$, Williane da Silva Freitas, \\ Alessandra D'Epifanio and Barbara Mecheri *(B) \\ Department of Chemical Science and Technologies, University of Rome Tor Vergata, Via della Ricerca Scientifica, \\ 00133 Rome, Italy; oliveira.maida@uniroma2.it (M.A.C.d.O.); pedro.pablo.machado.pico@uniroma2.it (P.P.M.P.); \\ williane.freitas@uniroma2.it (W.d.S.F.); alessandra.d.epifanio@uniroma2.it (A.D.) \\ * Correspondence: barbara.mecheri@uniroma2.it; Tel.: +39-06-7259-4488
}

Received: 25 June 2020; Accepted: 28 July 2020; Published: 30 July 2020

check for updates

Featured Application: Iron-based electrocatalysts were developed as oxygen-reducing catalysts for microbial fuel cell application.

\begin{abstract}
In this work, we synthesized new materials based on Fe(II) phthalocyanine (FePc), urea and carbon black pearls (BP), called Fe-N-C, as electrocatalysts for the oxygen reduction reaction (ORR) in neutral solution. The electrocatalysts were prepared by combining ball-milling and pyrolysis treatments, which affected the electrochemical surface area (ECSA) and electrocatalytic activity toward ORR, and stability was evaluated by cyclic voltammetry and chronoamperometry. Ball-milling allowed us to increase the ECSA, and the ORR activity as compared to the Fe-N-C sample obtained without any ball-milling. The effect of a subsequent pyrolysis treatment after ball-milling further improved the electrocatalytic stability of the materials. The set of results indicated that combining ball-milling time and pyrolysis treatments allowed us to obtain Fe-N-C catalysts with high catalytic activity toward ORR and stability which makes them suitable for microbial fuel cell applications.
\end{abstract}

Keywords: iron phthalocyanine; ball-milling; $\mathrm{M}-\mathrm{N}-\mathrm{C}$ electrocatalysts; oxygen reduction reaction; fuel cells

\section{Introduction}

Bioelectrochemical Systems (BESs) are classified as one of the most attractive renewable technology for energy conversion [1,2]. Among the various BESs, Microbial Fuel Cells (MFCs) allow simultaneous electrical energy harvesting and wastewater treatment [1,3-7] by the catalytic action of microorganisms, which oxidize the organic matter in the waste at the anode side of the cell to produce carbon dioxide, protons and electrons. Protons and electrons migrate through an external circuit and recombine with oxygen at the cathode side, producing water [1,4]. However, MFC technology is still in a pioneer stag, due to various critical issues to overcome. One of these issues is the slow kinetics of oxygen reduction reaction (ORR) at the cathode side and the need for a highly efficient catalyst for a fast reduction of oxygen to water involving a four-electron pathway [4,8-11]. Hence, the development of effective and low-cost electrocatalysts is of crucial importance to develop highly efficient and durable MFC systems.

In this context, many studies have been addressed to develop alternative catalysts to noble metals (i.e., platinum), which are expensive, rare and sensitive to poisoning [3,8]. Platinum-group-metal-free (PGM-free) catalysts represent a very promising category of new catalysts due to their tuneable composition based on transition metals $(\mathrm{Fe}, \mathrm{Ni}, \mathrm{Co}, \mathrm{Mn}, \mathrm{Cu}$ ) supported on carbon substrates (graphene, graphene oxide, carbon nanotubes, black pearls, carbon black and biochar), which are also doped with heteroatoms (N, P, S, O) [12-20] 
Among PGM-free catalysts, metal-nitrogen-carbon (M-N-C) materials have been widely investigated toward ORR in acidic and alkaline $\mathrm{pH}$, whereas the study of ORR in neutral media still accounts for few reports $[6,8,12,21,22]$. So far, attention has been paid to the development of Fe-N-C catalysts, and the efficiency of active sites in Fe-N-C composites has been ascribed to the coordination of iron to nitrogen heteroatoms in FeNx structure, which cause a beneficial effect on the direct conversion of oxygen to water via a four-electron mechanism $[1,8,10,18]$. In this context, the activation of carbon substrates via $\mathrm{N}$-doping is crucial for stabilizing the coordination of transition metal, besides helping to maintain a high density of FeNx active sites for ORR and avoid the aggregation phenomena of the catalyst $[3,23,24]$.

Among the various iron sources for FeN-C catalysts, Iron (II) phthalocyanine (FePc) has attracted a great interest due to its low-cost, tuneable electronic property, facile methods of synthesis, and low overpotential for oxygen reduction [1,3,4,6,9,12,25-31]. Dong and coworkers have shown that the poor electron conductivity and stability of phthalocyanine complexes increase when $\mathrm{FeN}_{4}$ macrocycles are incorporated on nitrogen-functionalized carbon supports and further submitted to pyrolysis treatment [32]. Yang et al. verified that carbon-supported FePc greatly enhances ORR activity, owing to the interaction of the macrocycle with the support, which modulates electronic properties through a delocalized $\pi$-electron cloud [33]. By tuning the surface chemistry and morphology of the carbon support, metal stabilization through $\pi-\pi$ interaction result in a good catalytic activity and durability in neutral media [34-36]. Surface area and porosity are also of paramount importance to increase catalytic activity towards ORR [37]. Two-dimensional (2D) $\mathrm{FeN}_{4}$ catalysts with high surface area and porous structure have indeed demonstrated good performance in terms of oxygen reduction activity and long-term stability due to a synergistic effect of the high density of active sites and porosity, which favours high-mass transfer [24]. In addition, thermal treatments are crucial for Fe-N coordination and catalytic stability [38]. As previously reported, metal-nitrogen coordination improves up to $400-900{ }^{\circ} \mathrm{C}$, while a higher temperature may cause a detrimental effect [39]. The use of multiple-step annealing high-temperature treatments on FeN-C leads to a catalyst with good conductivity, avoiding agglomeration phenomena and thus increasing catalyst stability $[21,39,40]$.

Ball-milling has been also combined with pyrolysis to further improve surface area and porosity of the resulting materials. The ball mill effects on catalyst morphology and overall performance depend on temperature, milling time and rotation rate, and catalyst/carbon ratio [24,37,39,41-45]. In particular, high-energy ball-milling not only allows efficient blending of carbon supports and macrocyclic complexes such as FePc, but also results in enhanced intermolecular $\pi-\pi$ interactions, while low-temperature preparation avoids destroying the $\mathrm{Fe}-\mathrm{N}$ coordination structure $[37,39,43-45]$. Also, a FePc/carbon mass ratio up to 1:1 was found to lead to a uniform adsorption, which corresponds to nearly two molecular layers of FePc on carbon particles, indicating a decrease in iron(II) phthalocyanine agglomeration [24]. The effect of ball-milling on physical and electrochemical properties of the resulting catalyst materials, including surface area, porosity and specific capacitance, was widely studied throughout in the literature [46-48], but its effect on ORR activity in neutral media is still poorly explored. This investigation is of paramount importance to assess the material's applicability in BESs.

This work focused on the preparation of FePc-N-C catalysts by anchoring FePc on nanostructured carbon black pearls by a four-step process: Substrate activation, dry impregnation, ball-milling and pyrolysis. To enhance ORR performance, ball-milling and pyrolysis parameters were optimized to improve the interaction between the $\mathrm{FeN}_{4}$ macrocycle with nanostructured carbon. The prepared materials showed high ORR activity in neutral media, thus being promising for application in BESs.

\section{Materials and Methods}

\subsection{Materials}

Treatment of carbon support: Carbon Black pearls 2000 (BP) were purchased by Cabot corporation (MA, US) and treated in refluxing concentrated $\mathrm{HNO}_{3} 65 \mathrm{wt} . \%$ at $90^{\circ} \mathrm{C}$ for $16 \mathrm{~h}$. Then, $\mathrm{BP}$ was filtered 
using a Whatman membrane filters nylon (pore size: $0.45 \mu \mathrm{m}$, diameter: $47 \mathrm{~mm}$ ) and a diaphragm vacuum pump (Vacuubrand GMBH). Then, the material was washed with distilled water until neutral $\mathrm{pH}$ was obtained, dried in an oven at $70{ }^{\circ} \mathrm{C}$ overnight and milled in mortar agate (treated BP was labelled as BPO).

Preparation of electrocatalysts: $0.5 \mathrm{~g}$ of BPO, $0.5 \mathrm{~g}$ of iron (II) phthalocyanine (FePc, Aldrich) and $2 \mathrm{~g}$ of $\mathrm{CH}_{4} \mathrm{~N}_{2} \mathrm{O}$ (Urea, VWR Chemicals) were mixed by hand using a mortar for $30 \mathrm{~min}$, and part of this sample was then pyrolyzed in an $\mathrm{Al}_{2} \mathrm{O}_{3}$-tube furnace (Forni De Marco, Italy) at $900{ }^{\circ} \mathrm{C}$ for $1 \mathrm{~h}$ under an $\mathrm{Ar}$ atmosphere, obtaining two samples labelled as FeNC and FeNC_P, respectively. In addition, a further part of FeNC sample $(2 \mathrm{~g})$ was ball-milled in a Zirconia jar $(\mathrm{V}=80 \mathrm{~mL})$ with 100 Zirconia balls (5-mm diameter) in a planetary ball-miller (Pulverisette 6, Fritsch $\mathrm{GmbH}$ ) for either 6 or 12 cycles of $30 \mathrm{~min}$ milling and 5-min pause at a rotation rate of $400 \mathrm{rpm}$, and then pyrolyzed at $900{ }^{\circ} \mathrm{C}$ for $1 \mathrm{~h}$ under Ar atmosphere, obtaining two samples labelled as FeNC_BM3_P and FeNC_BM6_P. Two further samples were obtained by ball-milling FeNC continuously for $1 \mathrm{~h}$ (FeNC_BM1) and then pyrolyzing as described before (FeNC_BM1_P).

Figure 1 shows a diagram illustrating the procedure for sample preparation, and Table 1 lists all the samples prepared with the corresponding label.

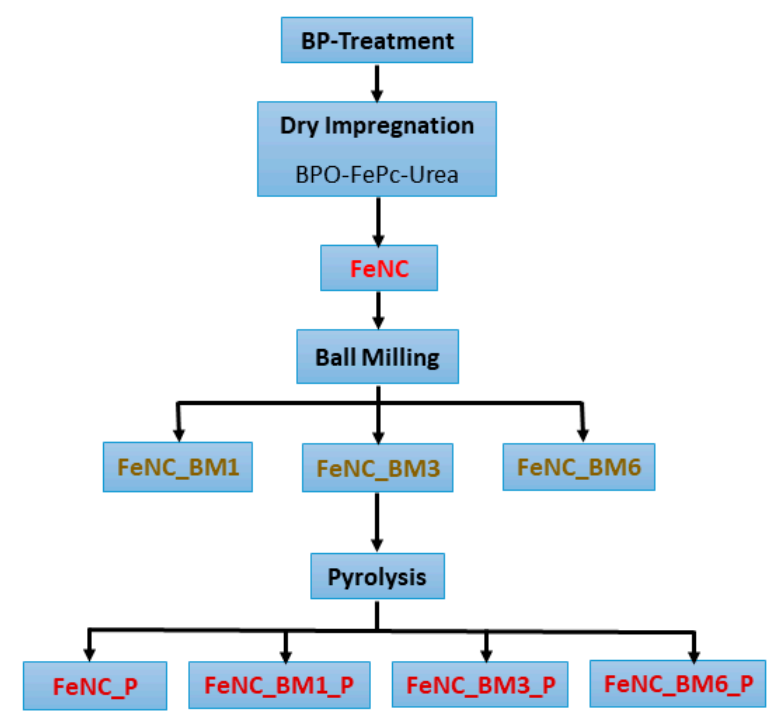

Figure 1. Electrocatalysts synthesis flowchart.

Table 1. List of the prepared electrocatalysts and the corresponding label.

\begin{tabular}{ccc}
\hline Sample Label & Ball Milling & Pyrolysis \\
\hline FeNC & $\mathrm{NO}$ & $\mathrm{NO}$ \\
FeNC_P & $\mathrm{NO}$ & $900{ }^{\circ} \mathrm{C}, 1 \mathrm{~h}, \mathrm{Ar}$ \\
FeNC_BM1 & $1 \mathrm{~h}$ & $\mathrm{NO}$ \\
FeNC_BM1_P & $1 \mathrm{~h}$ & $900{ }^{\circ} \mathrm{C}, 1 \mathrm{~h}, \mathrm{Ar}$ \\
FeNC_BM3 & 6 cycles (total time 3 h) & $\mathrm{NO}$ \\
FeNC_BM3_P & 6 cycles (total time 3 h) & $900{ }^{\circ} \mathrm{C}, 1 \mathrm{~h}, \mathrm{Ar}$ \\
FeNC_BM6 & 12 cycles (total time $6 \mathrm{~h}$ ) & $\mathrm{NO}$ \\
FeNC_BM6_P & 12 cycles (total time $6 \mathrm{~h}$ ) & $900{ }^{\circ} \mathrm{C}, 1 \mathrm{~h}, \mathrm{Ar}$ \\
\hline
\end{tabular}

\subsection{Methods}

Thermogravimetric analysis (TGA) was performed using a TGA/DSC1 Star System (Mettler Toledo) in $\mathrm{N}_{2}$ with a heating rate of $5{ }^{\circ} \mathrm{C} / \mathrm{min}$. The samples (mass ranging from $9 \mathrm{mg}$ to $24 \mathrm{mg}$ ), which was held in platinum sample holder with a cover having one vent central hole. 
Catalyst ink preparation: The catalyst ink was prepared by dispersing $0.2 \mathrm{mg}$ of catalyst in $270 \mu \mathrm{L}$ of DI water and $135 \mu \mathrm{L}$ of Isopropanol. This dispersion was treated in an ultrasonic bath (Elmasonic P $30 \mathrm{H}$, Elma Schmidbauer $\mathrm{GmbH}$ ) for $45 \mathrm{~min}$. Then, $50 \mu \mathrm{L}$ of Nafion solution ( $5 \mathrm{wt}$. $\%$ in lower aliphatic alcohols and water, Aldrich) were added to the dispersion and treated in the ultrasonic bath for further $15 \mathrm{~min}$. The ink was dropped $(7 \mu \mathrm{L})$ onto a working electrode (glassy carbon disk/platinum ring rotating ring disk electrode: RRDE AFE6R2GCPT, area $=0.2375 \mathrm{~cm}^{2}$, Pine Research Instrumentation), resulting in a catalyst loading of $0.15 \mathrm{mgcm}^{-2}$. Before use, the modified glassy carbon electrode was dried in a convection oven at $40^{\circ} \mathrm{C}$ for $4 \mathrm{~min}$.

Fourier Transform Infrared Spectroscopy (FTIR) was carried out by means of a FTIR100 spectrometer (Perkin Elmer) in transmittance mode. Samples were pelleted in $150 \mathrm{mg}$ of $\mathrm{KBr}$ using a Specac manual hydraulic press, by applying a pressure of 7 tons for $5 \mathrm{~min}$. The diameter of pellets was $13 \mathrm{~mm}$. X-Ray Diffraction (XRD) was carried out by means of a Philips PW1730 diffractometer with $\mathrm{Cu} \mathrm{K} \alpha$ radiation $(\lambda=1.5406 \AA)$.

Cyclic Voltammetry (CV). The catalytic activity toward ORR of the prepared materials was examined by cyclic voltammetry, using a VMP3 Potentiostat (Bio Logic Science Instrument) controlled by computer through EC-Lab V10.18 software. A conventional tree electrode cell was used. The reference electrode was saturated calomel electrode SCE (Amel 303/SCG/12), the auxiliary electrode was a platinum wire (Amel 805/SPG/12) and the glassy carbon disk RRDE modified with the catalyst layer as a working electrode. All potential values in the manuscript were measured vs. SCE and then converted to the reversible hydrogen electrode (RHE) scale, according to Equation (1):

$$
E(R H E)=E(S C E)+E^{0}(S C E)+0.0591 p H
$$

where $E^{0}(S C E)=0.241 \mathrm{~V}$.

$\mathrm{CV}$ experiment was carried out in $125 \mathrm{~mL}$ of neutral phosphate buffer solution (PBS), saturated in either nitrogen or oxygen atmosphere (gas purging for at least $20 \mathrm{~min}$ to obtain complete oxygen saturation of the media) at room temperature, with $10 \mathrm{mVs}^{-1}$ scan rate and $1.4 \mathrm{~V}$ to $-0.4 \mathrm{~V}$ vs. RHE potential window. Specific capacitance (Cs) was calculated by integrating capacitive current (CV curve in $\mathrm{N}_{2}$ atmosphere) over a $1.1 \mathrm{~V}$ vs. RHE potential window, according to Equation (2) [49]:

$$
\mathrm{Cs}=\frac{\mathrm{A}}{2 \mathrm{mk}(\Delta \mathrm{V})}
$$

where $\mathrm{Cs}$ is the specific capacitance $\left(\mathrm{Fg}^{-1}\right), \mathrm{A}$ is the integrated area of the CVs, $\mathrm{m}$ is mass of electrocatalyst at the electrode surface $(\mathrm{g}), \mathrm{k}$ is potential scan rate $\left(\mathrm{mVs}^{-1}\right)$ and $\Delta \mathrm{V}$ is the potential window. The electrochemical surface area (ECSA) was obtained by Equation (3) [50-52]:

$$
E C S A=\frac{C_{D L}}{C_{S}}
$$

where $C_{D L}$ is the double layer capacitance $\left(\mathrm{Fm}^{-2}\right)$, taken as $30 \mu \mathrm{Fcm}^{-2}$, as previously reported [18].

Stability tests were carried out by chronoamperometry. Current density was measured at $0.26 \mathrm{~V}$ vs. RHE for $10 \mathrm{~h}$, in $\mathrm{O}_{2}$-saturated phosphate-buffered saline (PBS) in static condition. The current density retention (Jretention) was calculated as follows:

$$
\text { Jretention }=\frac{J_{t}}{J_{t 0}} * 100
$$

where $J_{t}$ is the measured current density at time $t$ and $J_{t 0}$ is the initial current density. 


\section{Results and Discussion}

Figure 2a shows TGA curves of FePc, urea, carbon black pearls treated with nitric acid (BPO), and pristine carbon black pearls (BP). Whereas BP were thermally stable over the whole temperature range investigated, BPO had a total weight loss of $33.5 \%$ due to the splitting off of oxygen containing surface groups introduced with the treatment with nitric acid [6]. As far as urea is concerned, three main weight losses can be identified. In the first temperature region (room temperature to $230^{\circ} \mathrm{C}$ ), mass loss can be associated with urea decomposition to ammonium cyanate, cyanic acid (HNCO) and ammonia. As the temperature increased $\left(230^{\circ} \mathrm{C}-400^{\circ} \mathrm{C}\right), \mathrm{HNCO}$ can further react with undecomposed urea to produce different decomposition products that eventually decomposed to carbon dioxide and ammonia up to $400{ }^{\circ} \mathrm{C}[53]$.

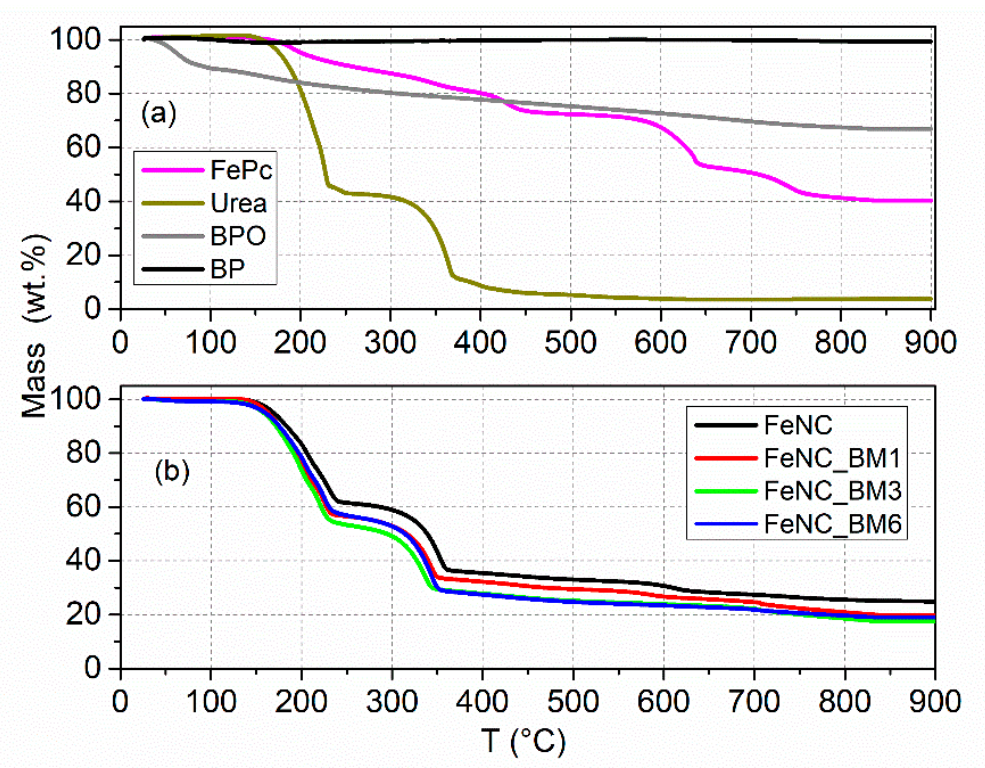

Figure 2. TGA curves of (a) precursors: FePc, urea, carbon black pearls treated with nitric acid (BPO), and pristine carbon black pearls (BP). (b) the prepared electrocatalysts before pyrolysis: FeNC, FeNC_BM1, FeNC_BM3 and FeNC_BM6.

In the case of $\mathrm{FePc}$, the first weight loss $\left(188{ }^{\circ} \mathrm{C}\right)$ did not involve a degradation step due to evaporation of adsorbed water. The second weight loss $\left(200-450{ }^{\circ} \mathrm{C}\right)$ was the first degradation stage, leading to phthalocyanine cores being decomposed, followed by a second $\left(550-650{ }^{\circ} \mathrm{C}\right)$ and third $\left(650-800{ }^{\circ} \mathrm{C}\right)$ degradation stage, overall corresponding to breakdown of the three-dimensional polymer structure and following decomposition of the breakdown products [54].

Weight loss in the prepared Fe-N-C electrocatalysts reflected weight losses of the precursors, and no substantial changes were observed among FeNC_BM1, FeNC_BM3 and FeNC_BM6 in terms of thermal stability. The first weight loss in Fe-N-C electrocatalysts can be ascribed to a combination of the splitting off of oxygen containing surface groups in $\mathrm{BPO}$, the evaporation of adsorbed water in both $\mathrm{BPO}$ and FePc, and the first step of urea decomposition. The second weight loss corresponds to the first thermal degradation step of FePc combined with further decomposition of unreacted urea. After $350^{\circ} \mathrm{C}$, the weight loss in Fe-N-C electrocatalysts was less pronounced and followed the decomposition of the FePc and urea breakdown products. Table 2 lists thermal parameters extrapolated from TGA curves for both precursors and electrocatalysts. 
Table 2. Weight losses and the corresponding midpoint temperatures (Tmid) from thermogravimetric analysis (TGA).

\begin{tabular}{cccccccc}
\hline Sample & $\begin{array}{c}\text { Weight Loss } \\
\mathbf{1}(\mathbf{w t .} \%)\end{array}$ & $\begin{array}{c}\mathbf{T}_{\mathbf{1}} \mathbf{m i d} \\
\left.\mathbf{(}{ }^{\circ} \mathbf{C}\right)\end{array}$ & $\begin{array}{c}\text { Weight Loss } \\
\mathbf{2}(\mathbf{w t .} \%)\end{array}$ & $\begin{array}{c}\mathbf{T}_{\mathbf{2}} \mathbf{m i d} \\
\left({ }^{\circ} \mathbf{C}\right)\end{array}$ & $\begin{array}{c}\text { Weight Loss } \\
\mathbf{3} \text { (wt. } \%)\end{array}$ & $\begin{array}{c}\mathbf{T}_{\mathbf{3}} \mathbf{m i d} \\
\left({ }^{\circ} \mathbf{C}\right)\end{array}$ & $\begin{array}{c}\text { Total Loss } \\
(\mathbf{w t .} \%)\end{array}$ \\
\hline FeNC & 25.6 & 187 & 13.5 & 227 & 25.0 & 340 & 75.0 \\
FeNC_BM1 & 31.0 & 186 & 11.9 & 223 & 23.4 & 329 & 80.3 \\
FeNC_BM3 & 31.1 & 183 & 14.8 & 219 & 24.3 & 323 & 82.3 \\
FeNC_BM6 & 27.8 & 184 & 15.0 & 223 & 25.7 & 333 & 80.7 \\
Urea & 55.0 & 207 & 2.6 & 242 & 31.1 & 353 & 97.1 \\
FePc & 7.2 & 188 & 20.3 & 360 & 20.0 & 617 & 60.4 \\
BPO & 7.4 & 56 & 3.6 & 82 & 5.4 & 156 & 33.5 \\
\hline
\end{tabular}

A structural analysis of Fe-N-C samples was carried out by FTIR spectroscopy and XRD.

Figure 3 a shows the FTIR spectrum of FeNC_BM1, FeNC_BM3 and FeNC_BM6 in a broad range of wavenumber (400-4000 $\left.\mathrm{cm}^{-1}\right)$, while Figure $3 \mathrm{~b}$ shows a portion of the same spectra in a reduced range of wavenumber $\left(500-1800 \mathrm{~cm}^{-1}\right)$. As a general comment, the FTIR spectrum of the three catalysts showed all the vibration bands of urea, and two main contributions of FePc at $1335 \mathrm{~cm}^{-1}$ and $727 \mathrm{~cm}^{-1}$, corresponding to the $\mathrm{C}=\mathrm{C}$ stretching vibration, and the $\mathrm{C}_{\text {arom. }}-\mathrm{H}$ out-of-plane bending vibration [55,56]. The FTIR spectra of FePc and urea, together with a complete assignment of all vibration bands, is reported in Figure S1 and Table S1, respectively, while the assignment of vibration band in the FeNC catalysts is reported in Table 3.
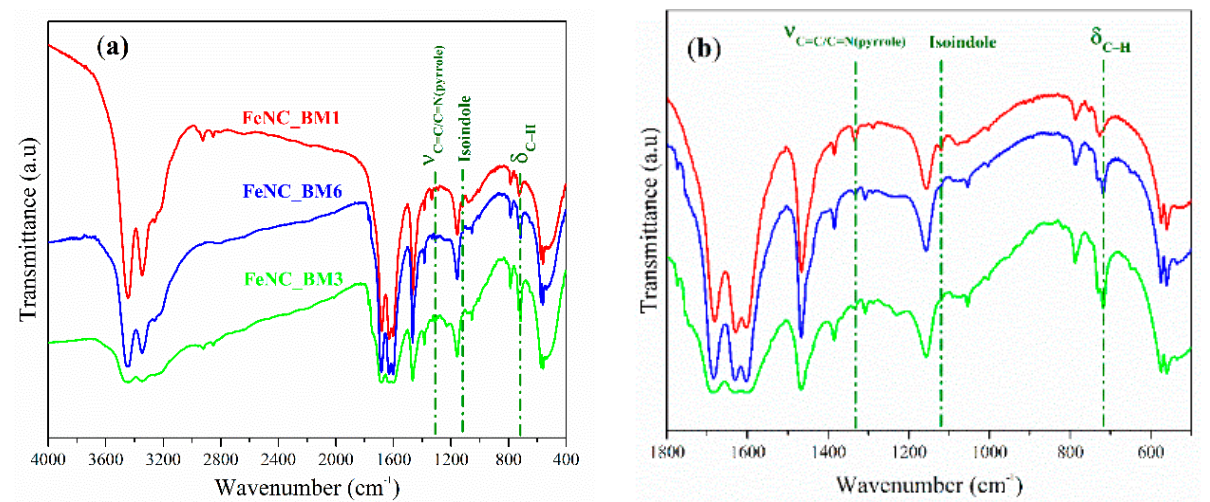

Figure 3. Fourier Transform Infrared (FTIR) spectra of FeNC_BM1, FeNC_BM3 and FeNC_BM6 at the (a) $400-4000 \mathrm{~cm}^{-1}$ and (b) (500-1800 $\mathrm{cm}^{-1}$ wavenumber range.

Table 3. Weight losses and the corresponding midpoint temperatures (Tmid) from TGA analysis.

\begin{tabular}{cccc}
\hline \multicolumn{3}{c}{ Wavenumber $\left(\mathbf{c m}^{-\mathbf{1}}\right)$} & Assignment \\
\hline FeNC_BM1 & FeNC_BM3 & FeNC_BM6 & \\
\hline 3443 & 3447 & 3454 & $v(\mathrm{~N}-\mathrm{H})$ \\
3347 & 3348 & 3347 & $v(\mathrm{~N}-\mathrm{H})$ \\
1682 & 1684 & 1682 & $v(\mathrm{C}=\mathrm{O})$ \\
1629 & 1630 & 1631 & $\delta(\mathrm{N}-\mathrm{H})$ \\
1602 & 1599 & 1604 & $\delta(\mathrm{C}=\mathrm{O}) /\left(\mathrm{NH}_{2}\right)$ \\
1467 & 1467 & 1467 & $v(\mathrm{C}-\mathrm{N})$ \\
1153 & 1158 & 1158 & $\delta(\mathrm{C}-\mathrm{H})($ in-plane + isoindole $)$ \\
1117 & 1120 & 1120 & Isoindole totally symmetric \\
717 & 721 & 719 & $\delta(\mathrm{C}-\mathrm{H})($ out-of-plane $)$ \\
\hline
\end{tabular}

On the other hand, a band due to symmetric vibrations of the isoindole fragments was clearly visible for FeNC_BM1 around $1120 \mathrm{~cm}^{-1}$, while it became a shoulder for FeNC_BM3 and FeNC_BM6. 
This finding suggests a higher vibrational activity of the isoindole groups on FeNC-BM1, indicating that increasing ball-milling time enhanced the interaction between FePc macrocycle and the carbon support.

Figure 4a shows XRD patterns of FeNC_BM1, FeNC_BM3 and FeNC_BM6. The XRD patterns of FePc, urea and BPO are shown in Figure S2. In the XRD pattern of the three catalysts, the major contribution of urea can be observed, while the more intense peak of graphitic carbon (from BPO support around $252 \theta^{\circ}$ ) and the peaks of FePc were hidden due to the greater crystalline contribution of urea.
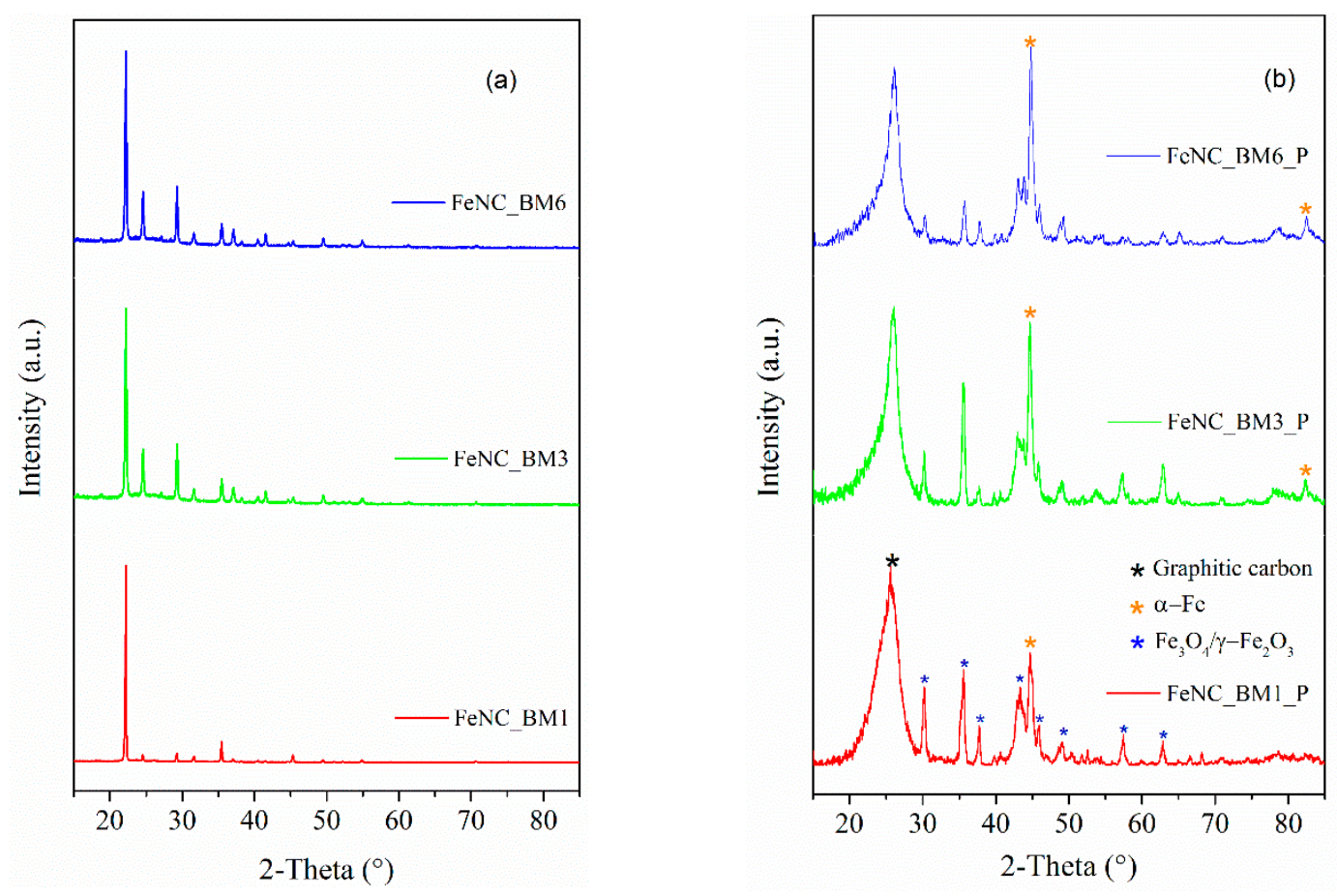

Figure 4. Intensity-normalized X-Ray diffractograms of (a) FeNC_BM1, FeNC_BM3 and FENC_BM6, and (b) FeNC_BM1_P, FeNC_BM3_P and FeNC_BM6_P.

However, as shown in Figure S3, the contribution of graphitic carbon was greater for FeNC-BM6, especially compared to FeNC_BM1. The contribution in the amorphous fraction was comprised in the $2 \theta$ range in which FePc exhibited a greater number of peaks (i.e., $15-852 \theta^{\circ}$ ). Therefore, we consider that the increase in ball-milling time led to an enhanced incorporation of FePc in BPO carbon support, in good agreement with FTIR results.

Figure $4 \mathrm{~b}$ shows the diffractograms of the catalysts obtained after heat treatment. The diffraction peak around $252 \theta$ degrees was observed for all materials, indicating a strong contribution of graphitic carbon to the XRD pattern of all catalysts, which is different from what observed for nonpyrolyzed catalysts. This was due to a precursor decomposition and breakdown during pyrolysis, as pointed out by TGA. Diffraction peaks for metal iron and iron oxide were also evident [57], and their intensity increased as the ball milling-time increased. This was particularly evident in the case of the diffraction peaks at $452 \theta^{\circ}$ and $822 \theta^{\circ}$ for the FeNC_BM6_P sample, suggesting an increase in iron content in the samples with the ball-milling time, in accordance with FTIR results.

To evaluate catalytic activity toward ORR of the prepared catalysts, cyclic voltammetry was carried out in either nitrogen- or oxygen-saturated phosphate buffer. No peaks were detected in $\mathrm{N}_{2}$-saturated PBS for both FeNC and FeNC_P (Figure 5), and the resulting capacitive current was much higher for FeNC_P as compared to FeN, because an expected effect of pyrolysis in increasing surface area of the catalyst. When the electrolyte was saturated with oxygen, a well-defined reduction peak around $0.6 \mathrm{~V}$ vs. RHE can be seen for both samples demonstrating the occurrence of ORR at the surface of Fe-N-C catalysts. The ORR peak was shifted toward more positive voltage values for 
FeNC_P, pointing at the beneficial effect of pyrolysis in enhancing ORR. ORR peak current density also increased, indicating an increased density of active sites after pyrolysis.

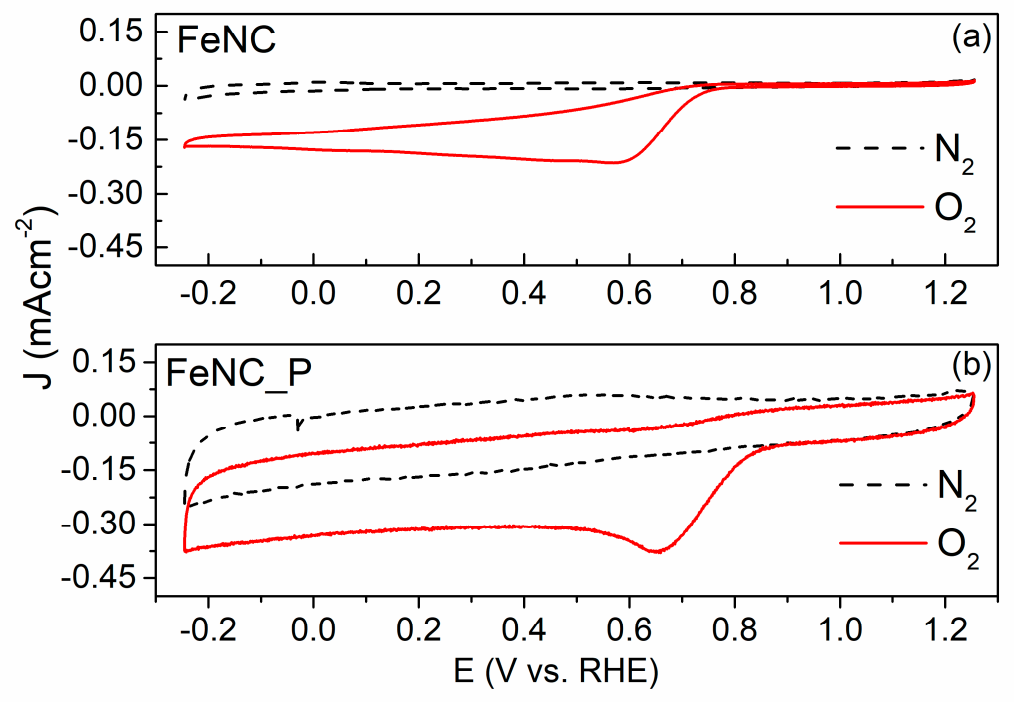

Figure 5. Cyclic voltammetry (CV) curves in $\mathrm{N}_{2}$ - (dash black lines) and $\mathrm{O}_{2}$-saturated (solid red lines) phosphate-buffered saline (PBS) for FeNC (a) and FeNC_P (b) samples.

The same characterization was carried out for all the prepared electrocatalysts: The samples prepared with different ball-milling times (FeNC_BM1, FeNC_BM3 and FeNC_BM6) and the samples obtained after a further pyrolysis treatment of the above-mentioned samples (FeNC_BM1_P, FeNC_BM3_P and FeNC_BM6_P). The corresponding CV curves are shown in Figure 6.
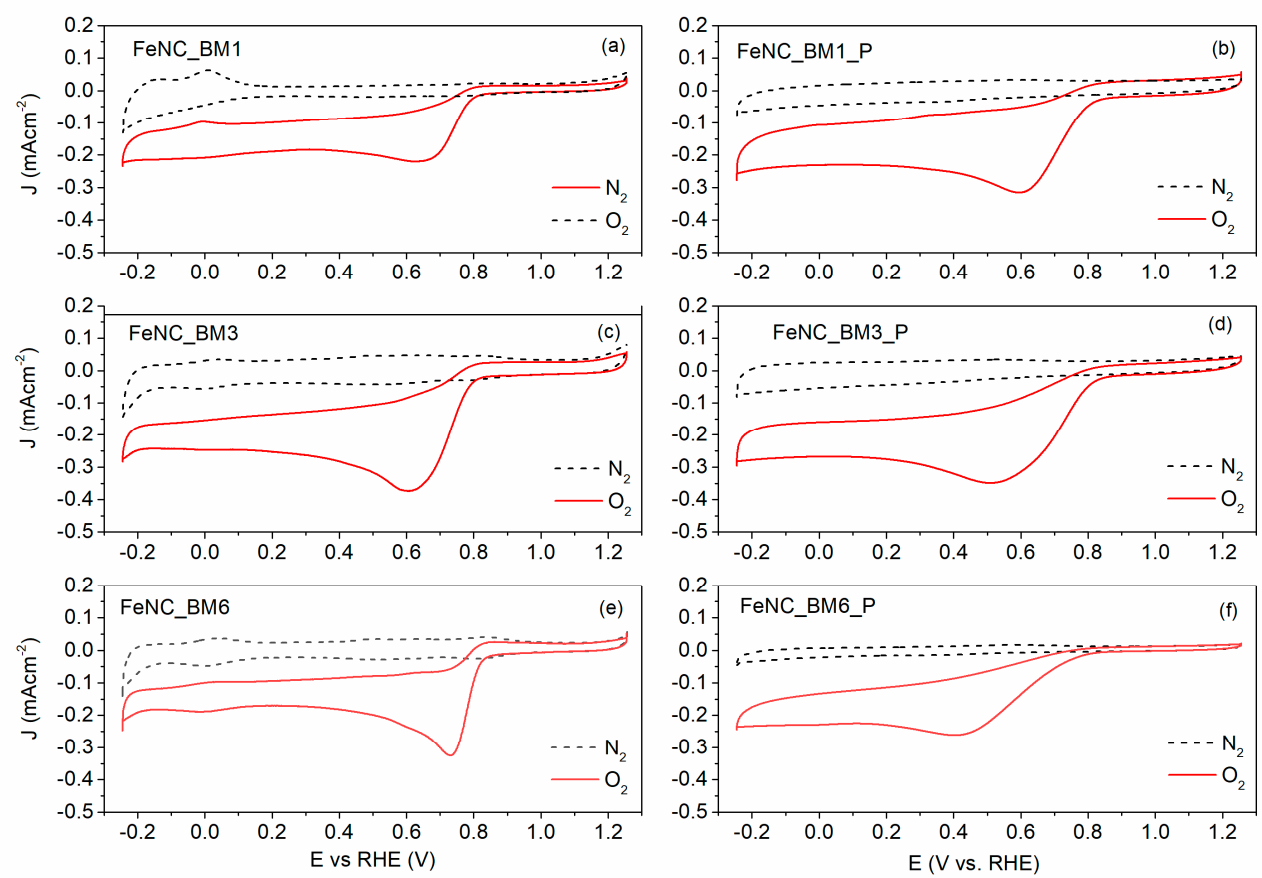

Figure 6. $\mathrm{CV}$ curves in $\mathrm{N}_{2}$ - (dash black lines) and $\mathrm{O}_{2}$-saturated (solid red lines) PBS for FeNC_BM1 (a), FeNC_BM1_P (b), FeNC_BM3 (c), FeNC_BM3_P (d), FeNC_BM6 (e) and FeBM6_P (f) samples.

$\mathrm{CV}$ analysis indicated that both ball-milling and pyrolysis affect capacitive current density values, ORR peak potential and peak current density. Electrochemical surface area (ECSA) was then 
calculated by integrating capacitive current, and the results are shown in Table 4, together with further electrochemical parameters extrapolated from CV analysis, such as ORR peak potential (Epr) and peak current density (Jpr).

Table 4. Electrochemical surface area (ECSA) and electrochemical parameters (oxygen reduction reaction (ORR) peak potential, $\mathrm{E}_{\mathrm{pr}}$, peak current density, $\mathrm{J}_{\mathrm{pr}}$, and current density retention (@ $0.26 \mathrm{~V}$ vs. RHE) after $10 \mathrm{~h}$, Jretention) of the prepared electrocatalysts.

\begin{tabular}{ccccc}
\hline Sample & ECSA $\left.\mathbf{( m}^{\mathbf{2}} \mathbf{g}^{-\mathbf{1}}\right)$ & $\mathbf{E}_{\mathbf{p r}} \mathbf{( V )}$ & $\mathbf{J}_{\mathbf{p r}}\left(\mathbf{m} \mathbf{A c m} \mathbf{c m}^{-\mathbf{2}}\right)$ & Jretention (\%) \\
\hline FeNC & 19 & 0.58 & 0.21 & 12 \\
FeNC_P & 146 & 0.65 & 0.38 & 30 \\
FeNC_BM1 & 54 & 0.63 & 0.22 & 12 \\
FeNC_BM1_P & 69 & 0.60 & 0.31 & 50 \\
FeNC_BM3 & 80 & 0.61 & 0.37 & 20 \\
FeNC_BM3_P & 70 & 0.51 & 0.35 & 75 \\
FeNC_BM6 & 46 & 0.73 & 0.32 & 65 \\
FeNC_BM6_P & 24 & 0.40 & 0.26 & 80 \\
\hline
\end{tabular}

As a general comment, ECSA values changed after either ball-milling time and subsequent pyrolysis, and variations in Epr and Jpr also took place. To identify a trend in ECSA, Epr and Jp after ball-milling and pyrolysis, those parameters were plotted in Figure 7 for nonpyrolyzed (Figure 7a) and pyrolyzed catalysts (Figure 7b).
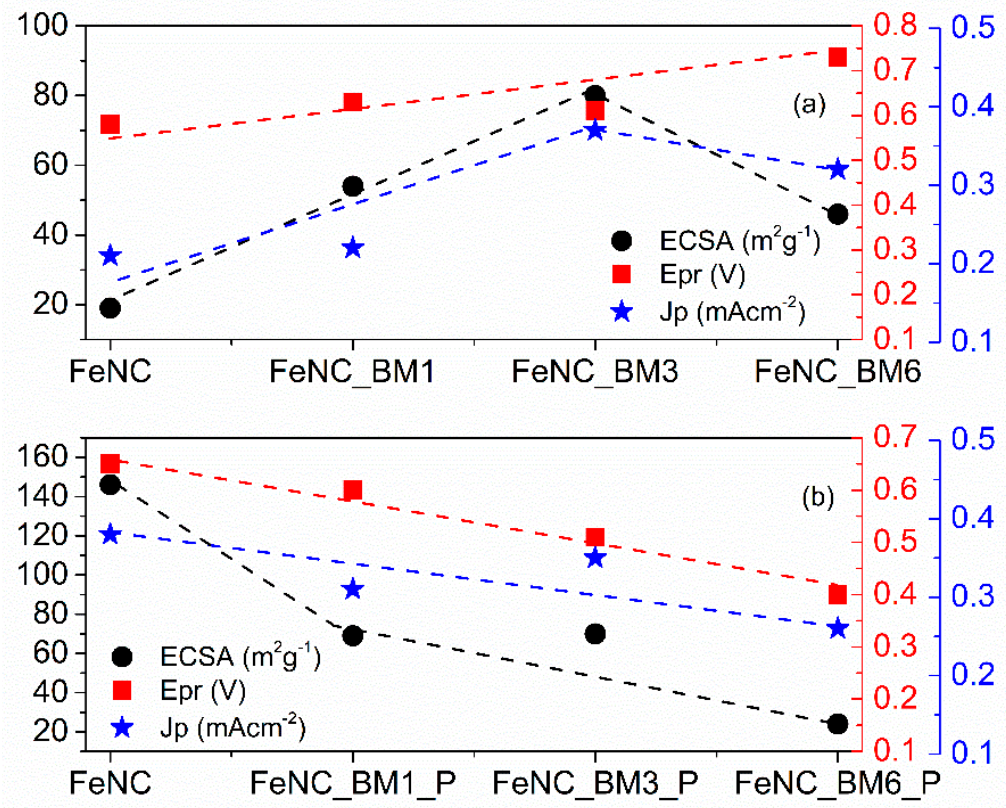

Figure 7. Trend of electrochemical surface area (ECSA), ORR peak potential (Epr) and peak current density (Jpr) of the prepared FeNC-based electrocatalyst before and after ball-milling (a) and pyrolysis (b) (symbols: experimental data; dash lines: guide for eyes).

In the case of nonpyrolyzed sample, ECSA increased as the ball-milling time increased up to $3 \mathrm{~h}$ $\left(80 \mathrm{~m}^{2} \mathrm{~g}^{-1}\right.$ for FeNC_BM3). After that, ECSA decreased for the sample prepared with $6 \mathrm{~h}$ of ball-milling time ( $46 \mathrm{~m}^{2} \mathrm{~g}^{-1}$ for FeNC_BM6). This finding indicates that increasing ball-milling is effective in increasing surface area of the electrocatalysts up to $3 \mathrm{~h}$, but longer ball-milling time may reverse the effect as previously reported [44,58]. Ball milling is indeed a very well-known method to increase materials surface area and porosity, contributing to breakdown of larger solid clusters into smaller ones, and optimizing ball-milling time is crucial to achieve desirable surface area and morphology [39]. 
ORR peak current density (ORR) followed the same trend as ECSA due to an increased density of active sites for higher ECSA samples. By contrast, Epr values increased as the ball-milling time increased, FeNC_BM6 sample having the more positive Epr value (Epr $=0.73 \mathrm{~V}$ vs. RHE).

The samples were further subjected to a pyrolysis treatment to overcome a possible heterogeneity in porosity and modification in surface chemistry induced by ball-milling, which may have contributed to decrease the active site utilization [59]. The pyrolysis step after ball-milling led to an increase in ECSA only for the sample prepared with no ball-milling $\left(146 \mathrm{~m}^{2} \mathrm{~g}^{-1}\right.$ for FeNC_P vs. $19 \mathrm{~m}^{2} \mathrm{~g}^{-1}$ for FeNC) and the sample obtained with $1 \mathrm{~h}$ of ball-milling time $\left(69 \mathrm{~m}^{2} \mathrm{~g}^{-1}\right.$ for FeNC_BM1_P vs. $54 \mathrm{~m}^{2} \mathrm{~g}^{-1}$ for FeNC_BM1). By contrast, the pyrolysis treatment led to a decrease in ECSA for ball-milling time higher than $1 \mathrm{~h}$. This can be ascribed to an agglomeration of solid clusters and pore growth between them, as previously reported by Martinaiou et al., who demonstrated that ESCA of Fe-N-C materials is reduced by a pyrolysis step after ball milling due to changes in porosity [60]. Epr and Jpr values were affected by pyrolysis with a similar trend as compared to that described for ECSA and illustrated in Figure 7.

The body of ECSA, Epr and Jp results indicated that ball-milling time in the range of 1-3 $\mathrm{h}$ allowed for the production of electrocatalysts with high ECSA, high density of ORR active sites (Jp), and good catalytic activity toward ORR (Epr). Longer ball-milling time (6 h) led to a catalyst (FeNC_BM6) with lower ECSA and Jp, but the lowest ORR overpotential (as can be seen from Epr value) still pointed at a good electrocatalytic activity toward ORR. The good catalytic activity of FeNC_BM6 can be explained by considering the enhanced FePc/carbon support interaction, as indicated by FTIR and XRD data. These findings confirm that ORR activity in the FeNC_catalysts arises from a combination of high surface area and the high content of $\mathrm{FeN}_{4}$ active sites well connect with the carbon support.

After pyrolysis, ECSA and Jp of FeBM3_P and FeBM6_P decreased, and Epr was shifted toward less positive values, indicating that pyrolysis is not effective in improving ORR performance of FeNC_BM3 and FeNC_BM6. This can be explained by the role of pyrolysis combined with long ball-milling time in increasing metal iron and $\mathrm{Fe}_{3} \mathrm{O}_{4} / \mathrm{Fe}_{2} \mathrm{O}_{3}$ content in the resulting materials. In fact, it has been previously proved that iron oxide has lower catalytic activity than nitrogen coordinated iron $\left(\mathrm{FeN}_{4}\right)$ sites. Metal iron has no ORR activity, also causing a reduction in the available area of $\mathrm{FeN}_{4}$ active sites [61].

As far as FeNC_BM1 sample is concerned, the pyrolysis induced an increase in ECSA and Jp, while Epr remained almost constant.

Along with ORR performance, electrocatalytic stability under operative conditions is also of paramount importance for determining the applicability of an electrocatalysts. Hence, the elect of ball-milling and pyrolysis on electrocatalytic stability was evaluated by chronoamperometry in $\mathrm{O}_{2}$-saturated PBS. Figure 8 shows current density retention (Jretention) as a function of time.

In the case of nonpyrolyzed samples (Figure 8a), current density decreased over time, and eventually reached a plateau after $8 \mathrm{~h}$. On the other hand, current density retention increased in the order FeNC < FeNC_BM1 < FeNC_BM3 > FeNC_BM6, indicating that ball-milling time was very effective in enhancing catalytic stability of Fe_N_C catalysts. Table 3 lists Jretention values for all samples: $6 \mathrm{~h}$ of ball-milling allowed retention up to $65 \%$ of initial current density after $10 \mathrm{~h}$ of operation. In the case of nonpyrolyzed samples (Figure $8 \mathrm{~b}$ ), current density retention was much higher than that of the corresponding nonpyrolyzed samples. This finding points toward the beneficial effect of pyrolysis in enhancing catalytic stability, and adequate Jretention values were obtained for FeNC_BM1_P, FeNC_BM3_P and FeNC_BM6_P (50\%, 75\% and 80\%, respectively). 


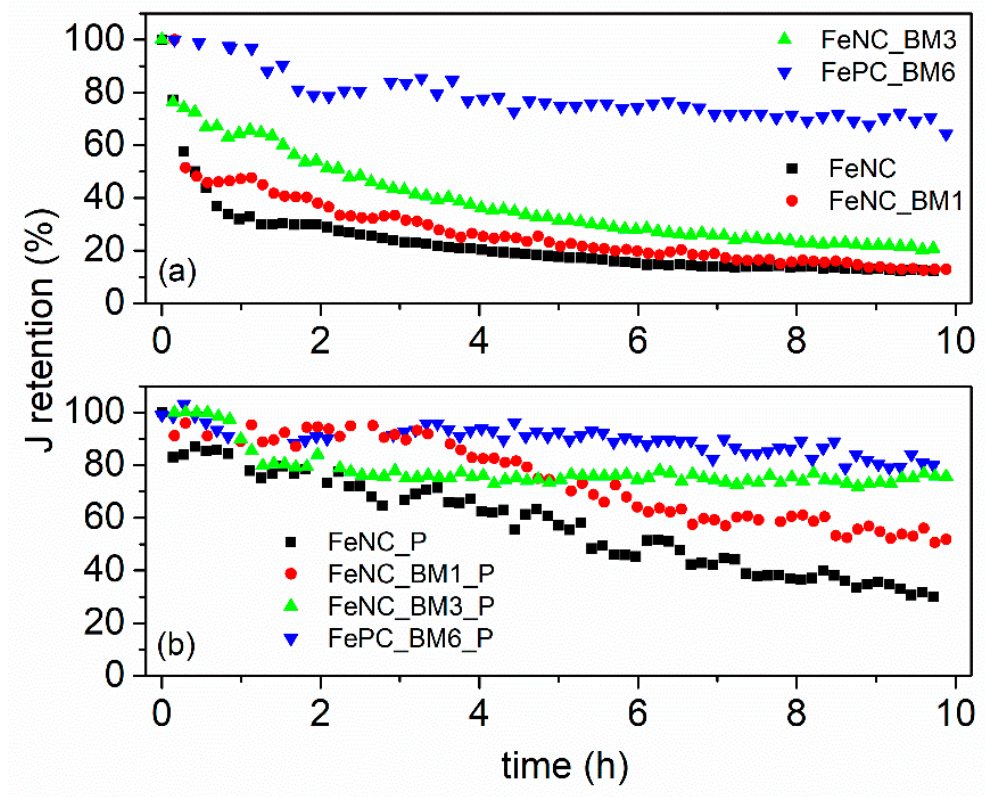

Figure 8. Current density retention (Jretention) @ 0.26 V vs. RHE over time for (a) nonpyrolyzed FeNC, FeNC_BM1, FeNC_BM3 and FeNC_BM6 and (b) pyrolyzed FeNC_P, FeNC_BM1_P, FeNC_BM3_P and FeNC_BM6_P.

\section{Contextualization into Existing Literature}

Fe-N-C catalysts can be considered as one of the most promising catalyst families to replace platinum at the cathode side of energy conversion devices such as fuel cells. Previous reports, which have focused on alkaline anion exchange membrane fuel cells, deeply investigated the ORR activity of Fe-N-C catalysts in alkaline environments, and found that optimizing the preparation procedure boosted catalytic activity and durability. Fe-N-C catalyst obtained by supporting FePc on graphene showed a ORR peak potential in the $0.7-0.84 \mathrm{~V}$ vs. RHE in an alkaline environment $[22,62,63]$. Oliveira et al. investigated ORR behaviour in an alkaline electrolyte of $\mathrm{FeN}_{4}$ macrocycles supported over carbon nanotubes and carbon spheres via a wet impregnation strategy. Those catalysts achieved a reduction potential of $0.82 \mathrm{~V}$ and $0.85 \mathrm{~V}$ vs. RHE, with an ECSA of $45 \mathrm{~m}^{2} \mathrm{~g}^{-1}$ and $57 \mathrm{~m}^{2} \mathrm{~g}^{-1}$, respectively [12]. Optimizing surface area and porosity improves the mass transport, and consequently, ORR performance [64]. Atanassov and coworkers demonstrated that a ball-mill treatment followed by pyrolysis induced a decrease in relative amount of both mesopores and macropores homogenizing morphology of Fe-N-C catalysts. In an alkaline environment, these materials directly catalysed oxygen reduction to water, with a reduction potential of $0.93 \mathrm{~V}$ vs. RHE [59].

In this context, the FeNC_BM6 catalyst discussed in this work showed an ORR peak potential as high as $0.73 \mathrm{~V}$ vs. RHE in neutral media. This value is very close to the values obtained for similar catalysts in alkaline environments, demonstrating that FeNC_BM6 is very active for ORR studies in $\mathrm{pH}$ environments, such as neutral, along with its electrochemical stability.

\section{Conclusions}

Ball-milling and pyrolysis strongly affect electrochemical surface area (ECSA), catalytic activity, and stability of Fe-N-C electrocatalysts prepared using Iron(II) phthalocyanine, urea and carbon black pearls as precursors. Ball-milling increased the ECSA, ORR peak potential (Epr) and peak current density (Jpr) as compared to the FeNC sample obtained without any ball-milling treatments. Different ball-milling times $(1 \mathrm{~h}, 3 \mathrm{~h}$, and $6 \mathrm{~h}$ ) were explored, and ORR performance of all the three catalysts prepared (FeNC_BM1, FeNC_BM3_FeNC_BM6) displayed a good catalytic activity toward ORR. In particular, $3 \mathrm{~h}$ and $6 \mathrm{~h}$ of ball-milling time allowed for the production of samples with the highest ECSA, Jp and Epr values due to its beneficial effect in enhancing the interaction between FePc 
and carbon support. Ball-milling also affected catalytic stability of the Fe-N-C catalysts, as increasing ball-milling time led to an increase of current density retention up to $65 \%$ for the FeNC_BM6 sample. The effect of a subsequent pyrolysis treatment after ball-milling on ORR catalytic activity and stability was also investigated. We found that pyrolysis after ball-milling had a detrimental effect on ECSA, Jp and Epr, with such a negative effect being more relevant for the samples obtained with higher ball-milling time (FeNC_BM3_P and FeNC_BM6_P). In fact, pyrolysis combined with long ball-milling time caused the increase in metal iron and iron oxide in the samples, which are less effective as ORR active sites as compared to nitrogen-coordinated iron. On the other hand, pyrolysis further improved electrocatalytic stability of the materials, allowing retention up to $80 \%$ of initial current density for FeNC_BM3_P and FeNC_BM3_P samples.

Overall, considering the requirements of high ORR catalytic activity and good stability under operative conditions, $6 \mathrm{~h}$ of ball-milling without any further pyrolysis was effective to prepare a Fe-N-C material with a good compromise between ORR activity and stability (FeNC_BM6). Also, $1 \mathrm{~h}$ of ball-milling followed by pyrolysis was effective in producing a Fe-C-materials with high ORR activity and stability (FeNC_BM1_P). Hence, FeNC_BM6 and FeNC_BM1_P can be good candidates for use at the cathode side of microbial fuel cells operating in neutral $\mathrm{pH}$.

Supplementary Materials: The following are available online at http://www.mdpi.com/2076-3417/10/15/5278/s1, Figure S1: FTIR spectra of FePc, FeNC-BM1 catalyst, and urea.; Figure S2: XRD patterns of BPO, urea, and FePc.; Figure S3: XRD patterns of FeNC_BM1 and FeNC_BM6.; Table S1: Characteristic IR bands of iron (II) phthalocyanine.; Table S2: Characteristic IR bands $\left(\mathrm{cm}^{-1}\right)$ of urea.

Author Contributions: Conceptualization, B.M. and A.D.; methodology, B.M., W.d.S.F and M.A.C.d.O.; investigation, B.M., A.D., P.P.M.P., W.d.S.F. and M.A.C.d.O.; resources, B.M., A.D., and M.A.C.d.O.; data curation, B.M., W.d.S.F, P.P.M.P., and M.A.C.d.O.; writing-original draft preparation, B.M. and M.A.C.d.O.; writing - review and editing, B.M.; supervision, B.M.; project administration, B.M.; funding acquisition, A.D. All authors have read and agreed to the published version of the manuscript.

Funding: This research was funded by the University of Roma Tor Vergata (Grant "BEYOND BORDERS 2019": Project Name: AEROBIC).

Acknowledgments: The authors acknowledge Cadia D'Ottavi (Dept. Chemical Science and Technologies of the University of Rome Tor Vergata) for her valuable technical support.

Conflicts of Interest: The authors declare no conflict of interest.

\section{References}

1. Costa De Oliveira, M.A.; D'Epifanio, A.; Ohnuki, H.; Mecheri, B. Platinum group metal-free catalysts for oxygen reduction reaction: Applications in microbial fuel cells. Catalysts 2020, 10, 475. [CrossRef]

2. Kodali, M.; Herrera, S.; Kabir, S.; Serov, A.; Santoro, C.; Ieropoulos, I.; Atanassov, P. Enhancement of microbial fuel cell performance by introducing a nano-composite cathode catalyst. Electrochim. Acta 2018, 265. [CrossRef] [PubMed]

3. Mecheri, B.; Ficca, V.C.A.; Costa de Oliveira, M.A.; D’Epifanio, A.; Placidi, E.; Arciprete, F.; Licoccia, S. Facile synthesis of graphene-phthalocyanine composites as oxygen reduction electrocatalysts in microbial fuel cells. Appl. Catal. B Environ. 2018, 237, 699-707. [CrossRef]

4. Costa de Oliveira, M.A.; Mecheri, B.; D'Epifanio, A.; Zurlo, F.; Licoccia, S. Optimization of PGM-free cathodes for oxygen reduction in microbial fuel cells. Electrochim. Acta 2020, 334, 135650. [CrossRef]

5. Pepe Sciarria, T.; Merlino, G.; Scaglia, B.; D’Epifanio, A.; Mecheri, B.; Borin, S.; Licoccia, S.; Adani, F. Electricity generation using white and red wine lees in air cathode microbial fuel cells. J. Power Sources 2015, 274, 393-399. [CrossRef]

6. Iannaci, A.; Mecheri, B.; D’Epifanio, A.; Lázaro Elorri, M.J.; Licoccia, S. Iron-nitrogen-functionalized carbon as efficient oxygen reduction reaction electrocatalyst in microbial fuel cells. Int. J. Hydrog. Energy 2016, 41, 19637-19644. [CrossRef]

7. Drendel, G.; Mathews, E.R.; Semenec, L.; Franks, A.E. Microbial Fuel Cells, Related Technologies, and Their Applications. Appl. Sci. 2018, 8, 2384. [CrossRef] 
8. Pepè Sciarria, T.; de Oliveira, M.A.C.; Mecheri, B.; D'Epifanio, A.; Goldfarb, J.L.; Adani, F. Metal-free activated biochar as an oxygen reduction reaction catalyst in single chamber microbial fuel cells. J. Power Sources 2020, 462. [CrossRef]

9. Costa de Oliveira, M.A.; Mecheri, B.; D’Epifanio, A.; Placidi, E.; Arciprete, F.; Valentini, F.; Perandini, A.; Valentini, V.; Licoccia, S. Graphene oxide nanoplatforms to enhance catalytic performance of iron phthalocyanine for oxygen reduction reaction in bioelectrochemical systems. J. Power Sources 2017, 356, 381-388. [CrossRef]

10. Mecheri, B.; Gokhale, R.; Santoro, C.; Costa De Oliveira, M.A.; D’Epifanio, A.; Licoccia, S.; Serov, A.; Artyushkova, K.; Atanassov, P. Oxygen Reduction Reaction Electrocatalysts Derived from Iron Salt and Benzimidazole and Aminobenzimidazole Precursors and Their Application in Microbial Fuel Cell Cathodes. Acs Appl. Energy Mater. 2018, 1, 5755-5765. [CrossRef]

11. Iannaci, A.; Mecheri, B.; D’Epifanio, A.; Licoccia, S. Sulfated zirconium oxide as electrode and electrolyte additive for direct methanol fuel cell applications. Int. J. Hydrog. Energy 2014, 39, 11241-11249. [CrossRef]

12. Costa de Oliveira, M.A.; Ficca, V.C.A.; Gokhale, R.; Santoro, C.; Mecheri, B.; D'Epifanio, A.; Licoccia, S.; Atanassov, P. Iron(II) phthalocyanine (FePc) over carbon support for oxygen reduction reaction electrocatalysts operating in alkaline electrolyte. J. Solid State Electrochem. 2020. [CrossRef]

13. Shahbazi Farahani, F.; Mecheri, B.; Majidi, M.R.; Placidi, E.; D’Epifanio, A. Carbon-supported Fe/Mn-based perovskite-type oxides boost oxygen reduction in bioelectrochemical systems. Carbon 2019, 145, 716-724. [CrossRef]

14. Shahbazi Farahani, F.; Mecheri, B.; Reza Majidi, M.; Costa de Oliveira, M.A.; D’Epifanio, A.; Zurlo, F.; Placidi, E.; Arciprete, F.; Licoccia, S. MnOx-based electrocatalysts for enhanced oxygen reduction in microbial fuel cell air cathodes. J. Power Sources 2018, 390, 45-53. [CrossRef]

15. Yang, J.; Tao, J.; Isomura, T.; Yanagi, H.; Moriguchi, I.; Nakashima, N. A comparative study of iron phthalocyanine electrocatalysts supported on different nanocarbons for oxygen reduction reaction. Carbon 2019, 145, 565-571. [CrossRef]

16. Cheng, W.; Yuan, P.; Lv, Z.; Guo, Y.; Qiao, Y.; Xue, X.; Liu, X.; Bai, W.; Wang, K.; Xu, Q.; et al. Boosting defective carbon by anchoring well-defined atomically dispersed metal- $\mathrm{N}_{4}$ sites for ORR, OER, and Zn-air batteries. Appl. Catal. B: Environ. 2020, 260, 118198. [CrossRef]

17. Santoro, C.; Gokhale, R.; Mecheri, B.; D’Epifanio, A.; Licoccia, S.; Serov, A.; Artyushkova, K.; Atanassov, P. Design of Iron(II) Phthalocyanine-Derived Oxygen Reduction Electrocatalysts for High-Power-Density Microbial Fuel Cells. ChemSusChem 2017, 10, 3243-3251. [CrossRef]

18. Yin, X.; Chung, H.T.; Martinez, U.; Lin, L.; Artyushkova, K.; Zelenay, P. PGM-Free ORR Catalysts Designed by Templating PANI-Type Polymers Containing Functional Groups with High Affinity to Iron. J. Electrochem. Soc. 2019, 166, F3240-F3245. [CrossRef]

19. Raggio, M.; Mecheri, B.; Nardis, S.; D’Epifanio, A.; Licoccia, S.; Paolesse, R. Metallo-Corroles Supported on Carbon Nanostructures as Oxygen Reduction Electrocatalysts in Neutral Media. Eur. J. Inorg. Chem. 2019, 2019, 4760-4765. [CrossRef]

20. Mecheri, B.; Iannaci, A.; D'Epifanio, A.; Mauri, A.; Licoccia, S. Carbon-supported zirconium oxide as a cathode for microbial fuel cell applications. ChemPlusChem 2016, 81, 80-85. [CrossRef]

21. Praats, R.; Käärik, M.; Kikas, A.; Kisand, V.; Aruväli, J.; Paiste, P.; Merisalu, M.; Leis, J.; Sammelselg, V.; Zagal, J.H.; et al. Electrocatalytic oxygen reduction reaction on iron phthalocyanine-modified carbide-derived carbon/carbon nanotube composite electrocatalysts. Electrochim. Acta 2020, 334. [CrossRef]

22. Komba, N.; Zhang, G.; Wei, Q.; Yang, X.; Prakash, J.; Chenitz, R.; Rosei, F.; Sun, S. Iron (II) phthalocyanine/N-doped graphene: A highly efficient non-precious metal catalyst for oxygen reduction. Int. J. Hydrog. Energy 2019, 44, 18103-18114. [CrossRef]

23. Bhowmick, G.D.; Kibena-Põldsepp, E.; Matisen, L.; Merisalu, M.; Kook, M.; Kaärik, M.; Leis, J.; Sammelselg, V.; Ghangrekar, M.M.; Tammeveski, K. Multi-walled carbon nanotube and carbide-derived carbon supported metal phthalocyanines as cathode catalysts for microbial fuel cell applications. Sustain. Energy Fuels 2019, 3, 3525-3537. [CrossRef]

24. Zhang, S.; Zhang, H.; Hua, X.; Chen, S. Tailoring molecular architectures of Fe phthalocyanine on nanocarbon supports for high oxygen reduction performance. J. Mater. Chem. A 2015, 3, 10013-10019. [CrossRef] 
25. Osmieri, L.; Monteverde Videla, A.H.A.; Ocón, P.; Specchia, S. Kinetics of Oxygen Electroreduction on Me-N-C (Me $=\mathrm{Fe}, \mathrm{Co}, \mathrm{Cu})$ Catalysts in Acidic Medium: Insights on the Effect of the Transition Metal. J. Phys. Chem. C 2017, 121, 17796-17817. [CrossRef]

26. Osmieri, L.; Escudero-Cid, R.; Monteverde Videla, A.H.A.; Ocón, P.; Specchia, S. Performance of a Fe-N-C catalyst for the oxygen reduction reaction in direct methanol fuel cell: Cathode formulation optimization and short-term durability. Appl. Catal. B Environ. 2017, 201, 253-265. [CrossRef]

27. Hong, M.; Nie, J.; Zhang, X.; Zhang, P.; Meng, Q.; Huang, J.; Xu, Z.; Du, C.; Chen, J. Facile solution synthesis of FeNx atom clusters supported on nitrogen-enriched graphene carbon aerogels with superb electrocatalytic performance toward the oxygen reduction reaction. J. Mater. Chem. A 2019, 7, 25557-25566. [CrossRef]

28. Nguyen, M.T.; Mecheri, B.; Iannaci, A.; D'Epifanio, A.; Licoccia, S. Iron/Polyindole-based Electrocatalysts to Enhance Oxygen Reduction in Microbial Fuel Cells. Electrochim. Acta 2016, 190, 388-395. [CrossRef]

29. Mecheri, B.; Iannaci, A.; D’Epifanio, A.; Nieto-Monge, M.J.; Lazaro, M.J.; Licoccia, S. Iron-Based Electrocatalysts Supported on Nanostructured Carbon to Enhance Oxygen Reduction in Microbial Fuel Cells. Ecs Trans. 2016, 72, 9-15. [CrossRef]

30. Osmieri, L.; Escudero-Cid, R.; Armandi, M.; Ocón, P.; Monteverde Videla, A.H.A.; Specchia, S. Effects of using two transition metals in the synthesis of non-noble electrocatalysts for oxygen reduction reaction in direct methanol fuel cell. Electrochim. Acta 2018, 266, 220-232. [CrossRef]

31. Osmieri, L.; Escudero-Cid, R.; Monteverde Videla, A.H.A.; Ocón, P.; Specchia, S. Application of a non-noble Fe-N-C catalyst for oxygen reduction reaction in an alkaline direct ethanol fuel cell. Renew. Energy 2018, 115, 226-237. [CrossRef]

32. Dong, G.; Huang, M.; Guan, L. Iron phthalocyanine coated on single-walled carbon nanotubes composite for the oxygen reduction reaction in alkaline media. Phys. Chem. Chem. Phys. 2012, 14. [CrossRef] [PubMed]

33. Yang, J.; Toshimitsu, F.; Yang, Z.; Fujigaya, T.; Nakashima, N. Pristine carbon nanotube/iron phthalocyanine hybrids with a well-defined nanostructure show excellent efficiency and durability for the oxygen reduction reaction. J. Mater. Chem. A 2017, 5. [CrossRef]

34. Taniguchi, T.; Tateishi, H.; Miyamoto, S.; Hatakeyama, K.; Ogata, C.; Funatsu, A.; Hayami, S.; Makinose, Y.; Matsushita, N.; Koinuma, M.; et al. A self-assembly route to an iron phthalocyanine/reduced graphene oxide hybrid electrocatalyst affording an ultrafast oxygen reduction reaction. Part. Part. Syst. Charact. 2013, 30. [CrossRef]

35. Cui, L.; Lv, G.; Dou, Z.; He, X. Fabrication of iron phthalocyanine/graphene micro/nanocomposite by solvothermally assisted $\pi-\pi$ Assembling method and its application for oxygen reduction reaction. Electrochim. Acta 2013, 106. [CrossRef]

36. Zhang, C.; Hao, R.; Yin, H.; Liu, F.; Hou, Y. Iron phthalocyanine and nitrogen-doped graphene composite as a novel non-precious catalyst for the oxygen reduction reaction. Nanoscale 2012, 4. [CrossRef]

37. Arul, A.; Pak, H.; Moon, K.U.; Christy, M.; Oh, M.Y.; Nahm, K.S. Metallomacrocyclic-carbon complex: A study of bifunctional electrocatalytic activity for oxygen reduction and oxygen evolution reactions and their lithium-oxygen battery applications. Appl. Catal. B: Environ. 2018, 220, 488-496. [CrossRef]

38. Zhao, F.; Harnisch, F.; Schröder, U.; Scholz, F.; Bogdanoff, P.; Herrmann, I. Application of pyrolysed iron(II) phthalocyanine and CoTMPP based oxygen reduction catalysts as cathode materials in microbial fuel cells. Electrochem. Commun. 2005, 7, 1405-1410. [CrossRef]

39. Ratso, S.; Sougrati, M.T.; Käärik, M.; Merisalu, M.; Rähn, M.; Kisand, V.; Kikas, A.; Paiste, P.; Leis, J.; Sammelselg, V.; et al. Effect of ball-milling on the oxygen reduction reaction activity of iron and nitrogen co-doped carbide-derived carbon catalysts in acid media. ACS Appl. Energy Mater. 2019, 2, 7952-7962. [CrossRef]

40. Praats, R.; Kruusenberg, I.; Käärik, M.; Joost, U.; Aruväli, J.; Paiste, P.; Saar, R.; Rauwel, P.; Kook, M.; Leis, J.; et al. Electroreduction of oxygen in alkaline solution on iron phthalocyanine modified carbide-derived carbons. Electrochim. Acta 2019, 299, 999-1010. [CrossRef]

41. Bui, T.T.; Le, X.Q.; To, D.P.; Nguyen, V.T. Investigation of typical properties of nanocrystalline iron powders prepared by ball milling techniques. Adv. Nat. Sci. Nanosci. Nanotechnol. 2013, 4. [CrossRef]

42. Tung, D.K.; Manh, D.H.; Phong, L.T.H.; Nam, P.H.; Nam, D.N.H.; Anh, N.T.N.; Nong, H.T.T.; Phan, M.H.; Phuc, N.X. Iron Nanoparticles Fabricated by High-Energy Ball Milling for Magnetic Hyperthermia. J. Electron. Mater. 2016, 45, 2644-2650. [CrossRef] 
43. Ratso, S.; Käärik, M.; Kook, M.; Paiste, P.; Aruväli, J.; Vlassov, S.; Kisand, V.; Leis, J.; Kannan, A.M.; Tammeveski, K. High performance catalysts based on Fe/N co-doped carbide-derived carbon and carbon nanotube composites for oxygen reduction reaction in acid media. Int. J. Hydrog. Energy 2019, 44, 12636-12648. [CrossRef]

44. Proietti, E.; Dodelet, J.-P. Ballmilling of Carbon Supports to Enhance the Performance of Fe-based Electrocatalysts for Oxygen Reduction in PEM Fuel Cells. Esc Trans. 2008, 393-404. [CrossRef]

45. Ramaswamy, N.; Mukerjee, S. Electrocatalysis of oxygen reduction on non-precious metallic centers at high pH Environments. Ecs Trans. 2010, 33, 1777-1785. [CrossRef]

46. Song, Q.S.; Chiu, C.H.; Chan, S.L.I. Effects of ball milling on the physical and electrochemical characteristics of nickel hydroxide powder. J. Appl. Electrochem. 2006, 36, 97-103. [CrossRef]

47. Eguchi, T.; Kanamoto, Y.; Tomioka, M.; Tashima, D.; Kumagai, S. Effect of ball milling on the electrochemical performance of activated carbon with a very high specific surface area. Batteries 2020, 6, 22. [CrossRef]

48. Choi, W.S.; Shim, W.G.; Ryu, D.W.; Hwang, M.J.; Moon, H. Effect of ball milling on electrochemical characteristics of walnut shell-based carbon electrodes for EDLCs. Microporous Mesoporous Mater. 2012, 155, 274-280. [CrossRef]

49. Zhang, Z.J.; Han, B.; Zhao, K.Y.; Gao, M.H.; Wang, Z.Q.; Yang, X.M.; Chen, X.Y. Surface modification of carbon materials by nitrogen/phosphorus co-doping as well as redox additive of ferrous ion for cooperatively boosting the performance of supercapacitors. Ionics 2020. [CrossRef]

50. Sancho, H.; Zhang, Y.; Liu, L.; Barevadia, V.G.; Wu, S.; Zhang, Y.; Huang, P.-W.; Zhang, Y.; Wu, T.-H.; You, W.; et al. $\mathrm{NiCO}_{2} \mathrm{Se}_{4}$ Nanowires as a High-Performance Bifunctional Oxygen Electrocatalyst. J. Electrochem. Soc. 2020, 167, 056503. [CrossRef]

51. Tovini, M.F.; Patil, B.; Koz, C.; Uyar, T.; Yilmaz, E. Nanohybrid structured $\mathrm{RuO}_{2} / \mathrm{Mn}_{2} \mathrm{O}_{3} / \mathrm{CNF}$ as a catalyst for $\mathrm{Na}-\mathrm{O}_{2}$ batteries. Nanotechnology 2018, 29. [CrossRef] [PubMed]

52. Lee, J.G.; Hwang, H.J.; Kwon, O.; Jeon, O.S.; Jang, J.; Shul, Y.G. Synthesis and application of hexagonal perovskite $\mathrm{BaNiO}_{3}$ with quadrivalent nickel under atmospheric and low-temperature conditions. Chem. Commun. 2016, 52, 10731-10734. [CrossRef] [PubMed]

53. Schaber, P.M.; Colson, J.; Higgins, S.; Thielen, D.; Anspach, B.; Brauer, J. Thermal decomposition (pyrolysis) of urea in an open reaction vessel. Thermochim. Acta 2004, 424, 131-142. [CrossRef]

54. Yurtseven, H.; Kaya, M.A.; Altindal, A.; Şener, M.K. Synthesis, thermal, and electrical properties of stilbene-bridged polymeric zinc phthalocyanine. Des. Monomers Polym. 2014, 17, 58-68. [CrossRef]

55. Monteverde Videla, A.H.A.; Osmieri, L.; Armandi, M.; Specchia, S. Varying the morphology of Fe-N-C electrocatalysts by templating Iron Phthalocyanine precursor with different porous $\mathrm{SiO}_{2}$ to promote the Oxygen Reduction Reaction. Electrochim. Acta 2015, 177, 43-50. [CrossRef]

56. Manivannan, M.; Nadu, T.; Rajendran, S.; Nadu, T.; Nadu, T. Investigation of Inhibitive Action of Urea- Zn2+ System in the Corrosion Control of Carbon Steel in Sea Water. Int. J. Eng. Sci. Technol. 2011, 3, 8048-8060.

57. Valvo, M.; Liivat, A.; Eriksson, H.; Tai, C.W.; Edström, K. Iron-Based Electrodes Meet Water-Based Preparation, Fluorine-Free Electrolyte and Binder: A Chance for More Sustainable Lithium-Ion Batteries? ChemSusChem 2017, 10, 2431-2448. [CrossRef]

58. Santos, D.F.M.; Soares, O.S.G.P.; Figueiredo, J.L.; Pereira, M.F.R. Effect of ball milling on the catalytic activity of cryptomelane for VOC oxidation. Environ. Technol. (UK) 2020, 41, 117-130. [CrossRef]

59. Artyushkova, K.; Rojas-Carbonell, S.; Santoro, C.; Weiler, E.; Serov, A.; Awais, R.; Gokhale, R.R.; Atanassov, P. Correlations between Synthesis and Performance of Fe-Based PGM-Free Catalysts in Acidic and Alkaline Media: Evolution of Surface Chemistry and Morphology. Acs Appl. Energy Mater. 2019, 2, 5406-5418. [CrossRef]

60. Martinaiou, I.; Wolker, T.; Shahraei, A.; Zhang, G.R.; Janßen, A.; Wagner, S.; Weidler, N.; Stark, R.W.; Etzold, B.J.M.; Kramm, U.I. Improved electrochemical performance of Fe-N-C catalysts through ionic liquid modification in alkaline media. J. Power Sources 2018, 375, 222-232. [CrossRef]

61. Jaouen, F.; Marcotte, S.; Dodelet, J.P.; Lindbergh, G. Oxygen reduction catalysts for polymer electrolyte fuel cells from the pyrolysis of iron acetate adsorbed on various carbon supports. J. Phys. Chem. B 2003, 107, 1376-1386. [CrossRef]

62. Cheng, Y.; Wu, X.; Veder, J.; Thomsen, L.; Jiang, S.P.; Wang, S. Tuning the Electrochemical Property of the Ultrafine Metaloxide Nanoclusters by Iron Phthalocyanine as Efficient Catalysts for Energy Storage and Conversion. Energy Environ. Mater. 2019, 2, 5-17. [CrossRef] 
63. Qiu, X.; Yan, X.; Pang, H.; Wang, J.; Sun, D.; Wei, S.; Xu, L.; Tang, Y. Isolated Fe Single Atomic Sites Anchored on Highly Steady Hollow Graphene Nanospheres as an Efficient Electrocatalyst for the Oxygen Reduction Reaction. Adv. Sci. 2019, 6. [CrossRef]

64. Fu, X.; Zamani, P.; Choi, J.Y.; Hassan, F.M.; Jiang, G.; Higgins, D.C.; Zhang, Y.; Hoque, M.A.; Chen, Z. In Situ Polymer Graphenization Ingrained with Nanoporosity in a Nitrogenous Electrocatalyst Boosting the Performance of Polymer-Electrolyte-Membrane Fuel Cells. Adv. Mater. 2017, 29. [CrossRef] [PubMed] 